\title{
Adipose-derived stem cells promote peripheral nerve repair
}

Gui-Bo Liư, ${ }^{1,2}$ Yong-Xia Cheng', Yu-Kuan Feng ${ }^{2}$, Chao-Jian Pang1, Qi Li ${ }^{1}$, Ying Wang ${ }^{1,2}$, Hua Jia ${ }^{1}$, Xiao-Jie Tong ${ }^{1}$

1Department of Human Anatomy, The Basic College of Medical Sciences, China Medical University, Shenyang, China

2Department of Human Anatomy, Mudanjiang Medical College, Mudanjiang, China 3Department of Pathology, Mudanjiang Medical College, Mudanjiang, China

Submitted: 10 December 2010

Accepted: 11 May 2011

Arch Med Sci 2011; 7, 4: 592-596

DOI: 10.5114 /aoms.2011.24127

Copyright (c) 2011 Termedia \& Banach

\section{Abstract}

Introduction: Recent evidence suggests that the implantation of bone marrowderived mesenchymal stem cells improves peripheral nerve regeneration. In this study we aimed to investigate whether adipose-derived stem cells (ADSCs) can be used for peripheral nerve repair.

Material and methods: In a rat model, nerve regeneration was evaluated across a $15 \mathrm{~mm}$ lesion in the sciatic nerve by using an acellular nerve injected with allogenic ADSCs. The walking behaviour of rats was measured by footprint analysis, and electrophysiological analysis and histological examination were performed to evaluate the efficacy of nerve regeneration.

Results: Cultured ADSCs became morphologically homogeneous with a bipolar, spindle-like shape after ex vivo expansion. Implantation of ADSCs into the rat models led to (i) improved walking behaviour as measured by footprint analysis, (ii) increased conservation of muscle-mass ratio of gastrocnemius and soleus muscles, (iii) increased nerve conduction velocity, and (iv) increased number of myelinated fibres within the graft.

Conclusions: Adipose-derived stem cells could promote peripheral nerve repair in a rat model. Although the detailed mechanism by which ADSCs promote peripheral nerve regeneration is being investigated in our lab, our results suggest that ADSCs transplantation represents a powerful therapeutic approach for peripheral nerve injury.

Key words: adipose-derived stem cells, peripheral nerve repair, cell transplantation, sciatic nerve.

\section{Introduction}

Mesenchymal stem cells (MSCs) are an attractive cell source for the regeneration of nerve tissue due to their self-renewal ability, high growth rate and multi-potent differentiation properties [1]. In particular, the implantation of bone marrow-derived mesenchymal stem cells (BMMSCs) has been shown to exert a beneficial effect on peripheral nerve regeneration [2-5]. However, it is a highly invasive and painful procedure to isolate BMMSCs and the frequency of MSCs in bone marrow is relatively low [6]. Therefore, an alternative cell source is in urgent demand [7, 8].

Adipose-derived stem cells (ADSCS) have similar phenotypic and gene expression profiles to BMMSCs $[9,10]$, but have unique advantages: they

\author{
Corresponding author: \\ Prof. Xiao-Jie Tong \\ Department of Human \\ Anatomy \\ 92 Bei'erma Lu \\ Heping District \\ Shenyang 110011, China \\ Phone: 86-13386887538 \\ E-mail: txjcmu@yahoo.com.cn
}


can be harvested easily by a safe and conventional liposuction procedure from subcutaneous fat tissue; the frequency of ADSCs in adipose tissue is much higher than that of MSCs in bone marrow [11]; and ADSCs proliferate significantly faster than BMMSCs $[12,13]$. The apparent advantages of ADSCs led us to investigate whether they may be ideal transplantable cells for peripheral nerve repair. In this study we employed a rat model of peripheral nerve injury and demonstrated that implantation of ADSCs promotes peripheral nerve repair.

\section{Material and methods}

\section{Preparation and characterization of adipose- derived stem cells}

Rat ADSCs were isolated as described previously [14]. Briefly, the inguinal fat pad was harvested from a 4-week old male Wistar rat and the adipose tissue was carefully dissected. The adipose tissue was digested using collagenase type I (Gibco, USA) and then dissociated mechanically. The suspension was centrifuged to separate the floating adipocytes from the stromal vascular fraction. The cells in the stromal vascular fraction were cultured in DMEM (Gibco) supplemented with $10 \%$ fetal bovine serum (FBS, Gibco) and the culture medium was changed $24 \mathrm{~h}$ later to eliminate the non-adherent cells. The cells were passaged 3-5 times before being used for subsequent experiments. To characterize the multi-potential differentiation capacity of ADSCs, the cells grown to at least $80 \%$ confluence were treated for 3 weeks with either osteogenic induction medium or adipogenic induction medium. Osteogenic induction medium was DMEM supplemented with 10\% FBS, $0.1 \mu \mathrm{M}$ dexamethasone, $50 \mu \mathrm{M}$ ascorbate-2-phosphate, and $10 \mathrm{mM} \beta$-glycerophosphate. Adipogenic induction medium was DMEM supplemented with $10 \%$ FBS, $0.5 \mathrm{mM}$ isobutyl-methylxanthine (IBMX), $1 \mu$ M dexamethasone, $10 \mu \mathrm{M}$ insulin, and $200 \mu \mathrm{M}$ indomethacin. Rat ADSCs were then stained with Alizarin Red S or OilRed $\mathrm{O}$ to confirm the osteogenic and adipogenic differentiation, respectively.

\section{In vitro construction of nerve graft}

A total of $2 \times 10^{6}$ ADSCs in $100 \mu$ DMEM were injected into a $1.5-\mathrm{cm}$ long acellular nerve allograft using a microinjector under an SXP-10 microscope at $10 \times$ magnification. To perform the injection, the microinjector was inserted through the full length of the nerve section, and cells were injected in equal volumes at four evenly spaced points as the injector was withdrawn. Another set of acellular nerve was used as the control group with no ADSCladen grafts, in which $100 \mu$ l DMEM was injected into the nerve grafts. The nerve grafts were then incubated in DMEM supplemented with $10 \%$ FBS in a humidified atmosphere with $5 \% \mathrm{CO}_{2}$ at $37^{\circ} \mathrm{C}$ for $48 \mathrm{~h}$ after which they were quickly used for in vivo experiments.

\section{Grafting procedure}

Twenty adult female Wistar rats (200-250 g), divided into ADSC-treated $(n=10)$ and control $(n=10)$ groups, were anesthetized with chloral hydrate $(350 \mathrm{mg} / \mathrm{kg})$ during all surgical procedures. After skin incision, the sciatic nerve was exposed using a muscle splitting incision. With the aid of an operation microscope, the right sciatic nerve (15-mm) was severed and removed near the obturator tendon in the mid-thigh. A 15-mm nerve graft was interposed into this nerve gap. The graft was coapted to the host nerve stumps by epineurial neurorrhaphy using one 9-0 Ethilon suture at each end. The ADSC-treated group received $A D S C$-laden grafts and the control group received non-ADSC-laden grafts. Both proximal and distal nerve stumps were anchored into the graft with 9-0 nylon microsutures, and the skin was closed with wound clips.

\section{Walking-track analysis}

Functional recovery was assessed by calculating the sciatic functional index (SFI) value [15]. SFI = $-38.3[($ EPL-NPL)/NPL] + 109.5[(ETS-NTS)/NTS $]+$ $+13.3[($ EIT-NIT)/NIT] -8.8 based on analysis of walking tracks $[16,17]$. Postoperatively, animals were assessed every 4 weeks to week 12 . The investigators were blinded to the animal groups during walking-track analysis.

\section{Electrophysiological analysis}

The rats were anesthetized with chloral hydrate (350 mg/kg) and the right sciatic nerve was exposed thoroughly. A crook-shaped silver needle electrode was placed on the proximal end and distal end of grafts. The proximal end was stimulated, and was record at the distal end. The distance between the two electrodes was measured with a sliding caliper of $0.2 \mathrm{~mm}$ precision. Nerve conduction velocity, latent period, and peak amplitude were recorded.

\section{Weight of the gastrocnemius and soleus muscles}

The rats were anaesthetized with chloral hydrate (350 mg/kg) 12 weeks after operation. The gastrocnemius and soleus muscles were harvested from the experimental and control sides, tendons were trimmed and muscles were weighed. A conservation muscle-mass ratio was recorded for each animal by dividing the experimental-side muscle mass by the control-side muscle mass $[18,19]$. 

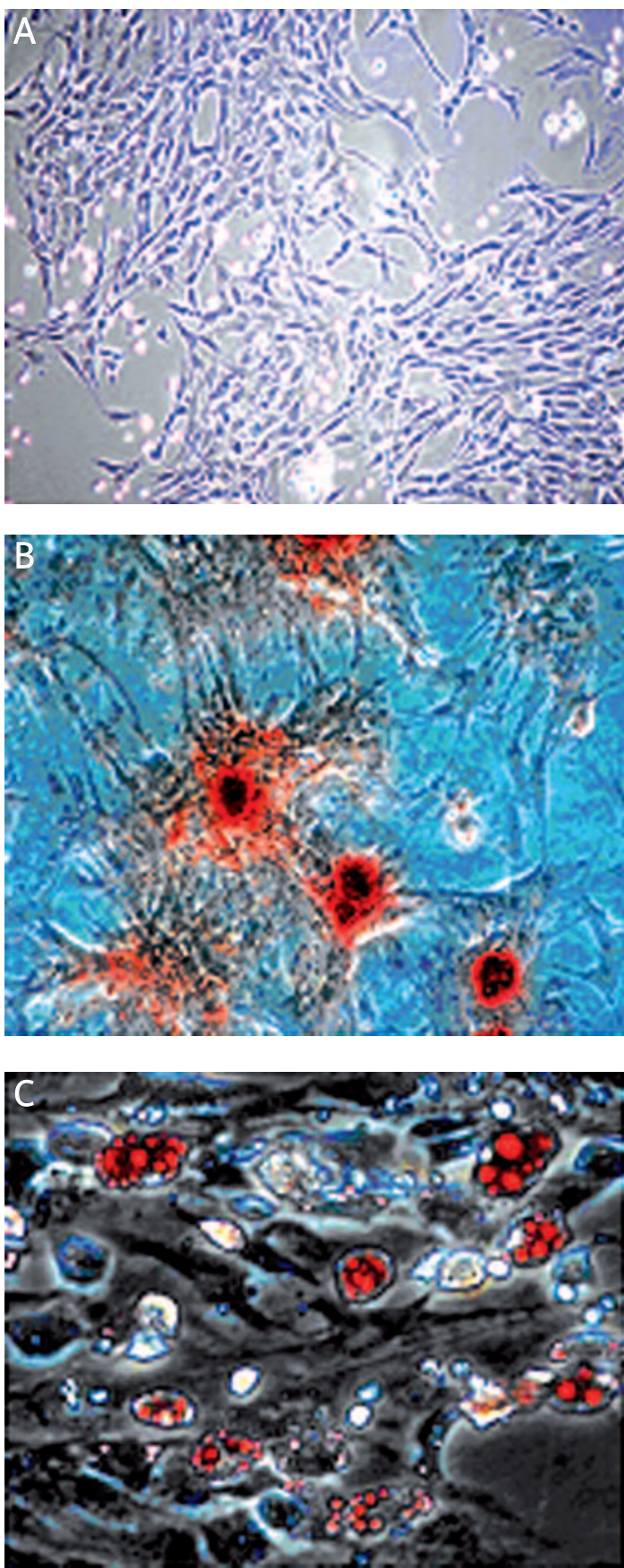

Figure 1. Rat ADSCs exhibit properties of stem cells. Rat ADSCs were passaged 3-5 times after initial plating of the primary culture. A - under phase contrast microscope, cultured ADSCs appeared as spindle-shaped. Rat ADSCs could undergo multilineage differentiation, including osteogenesis (B) and adipogenesis (C), as visualized by staining with Alizarin Red $\mathrm{S}$ or Oil-Red $\mathrm{O}$, respectively (light microscope, $\times 200$ )

\section{Histological examination}

The segments of the nerves were immersed in $2.5 \%$ Na-cacodylate-buffered glutaraldehyde solution for $2 \mathrm{~h}$, and fixed for $2 \mathrm{~h}$ in $2 \% \mathrm{Na}$-Cacodylate-buffered osmium tetroxide, then serially dehydrated in increasing concentrations of ethanol, infiltrated and embedded in Epon 812 (Ted Pella, (A, USA). A 1- $\mu$ m-thick cross-section was obtained and then stained with toluidine blue to evaluate the efficacy of nerve regeneration.

\section{Statistical analysis}

The data were expressed as mean \pm SD and analysed by SPSS 13.0 software. Analysis of variance was used for significant difference test. Student's $t$-test was used for inter-group comparison. Value of $p<0.05$ was considered statistically significant.

\section{Results}

\section{Characterization of cultured adipose-derived stem cells}

Rat ADSCs within 3-5 passages appeared as a monolayer of large and flat cells (Figure $1 \mathrm{~A}$ ). When induced with appropriate lineage-specific induction medium, ADSCs underwent adipogenesis (Figure $1 \mathrm{~B}$ ) and osteogenesis (Figure $1 \mathrm{C}$ ), demonstrating that we successfully isolated ADSCs with stem cell characteristics.

\section{Adipose-derived stem cells implantation promotes nerve regeneration}

None of the 20 rats developed any serious postsurgical complications. Wounded tissues healed spontaneously, and there were no trophic ulcerations on the operated legs. About 3 or 4 weeks later, muscular atrophy of operated legs of control groups was obvious. The adherence was very slight between the grafts and around tissues with no formation of neuroma.

To evaluate the efficacy of ADSCs in functional improvement in peripheral nerve injured rats, we first compared the SFI between the ADSC-treated group and the control group. Typical walking tracts obtained from the rats 12 weeks after surgery are shown in Figure 2. The SFI analysis showed that functional recovery of the ADSC-treated group was significant better than that of the control group $(p<0.05)$ (Table I).

In addition, electrophysiological analysis revealed higher nerve conduction velocities and peak amplitudes, and shorter incubation period in the ADSC-treated group compared to the control group and the differences were statistically significant $(p<0.05)$ (Table II). After 12 weeks of nerve injury, the right gastrocnemius and soleus muscles degenerated and lost weight. The muscle-mass conservation ratio showed that ADSC transplantation could reduce sciatic nerve injury-induced weight loss (Table II).

To evaluate the regeneration efficacy of myelinated nerves after grafting with nerve grafts, 


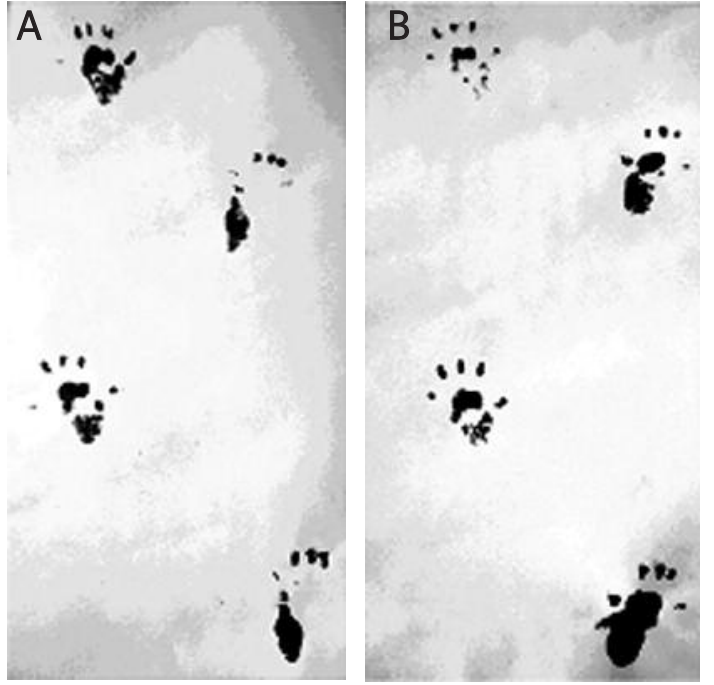

Figure 2. Walking tract analysis. A - control group. B-ADSC-treated group
Table I. Functional nerve regeneration (SFI)

\begin{tabular}{|lcc|}
\hline $\begin{array}{l}\text { Postoperative } \\
\text { week }\end{array}$ & Control group & $\begin{array}{c}\text { ADSC-treated } \\
\text { group }\end{array}$ \\
\hline 4 & $-97.50 \pm 0.12$ & $-96.18 \pm 0.57$ \\
\hline 8 & $-90.70 \pm 0.09$ & $-82.82 \pm 0.49^{\star}$ \\
\hline 12 & $-86.79 \pm 0.4$ & $-80.51 \pm 0.09^{\star}$ \\
\hline
\end{tabular}

Values were mean $\pm S D,{ }^{*} p<0.05$ compared to control group

we examined semi-thin sections of the distal ends of the grafts. Light microscopic examination of toluidine blue-stained cross-sections of these distal ends revealed an obvious difference between the experimental and control group. In particular, the experimental ADSC grafts had a comparatively higher density of well-myelinated fibres in the distal portion of the graft (Figure $3 \mathrm{~B}$ ). In contrast, the control grafts showed a relatively low density of well-

Table II. Electrophysiological index and conservation muscle-mass ratio of gastrocnemius and soleus muscles $(n=10)$

\begin{tabular}{|lcccc|}
\hline Group conservation & $\begin{array}{c}\text { Nerve conduction } \\
\text { velocity }[\mathrm{m} / \mathrm{s}]\end{array}$ & $\begin{array}{c}\text { Incubation period } \\
{[\mathrm{ms}]}\end{array}$ & $\begin{array}{c}\text { Peak amplitude } \\
{[\mathrm{mm}]}\end{array}$ & $\begin{array}{c}\text { Muscle-mass ratio } \\
{[\%]}\end{array}$ \\
\hline Control & $8.16 \pm 0.42$ & $1.85 \pm 0.05$ & $3.04 \pm 0.31$ & $38.13 \pm 3.76$ \\
\hline ADSC-treated & $10.72 \pm 0.58^{*}$ & $1.39 \pm 0.07^{*}$ & $6.29 \pm 0.52^{*}$ & $44.50 \pm 4.63^{*}$ \\
\hline
\end{tabular}

Values were mean $\pm S D,{ }^{*} p<0.05$ compared to control group
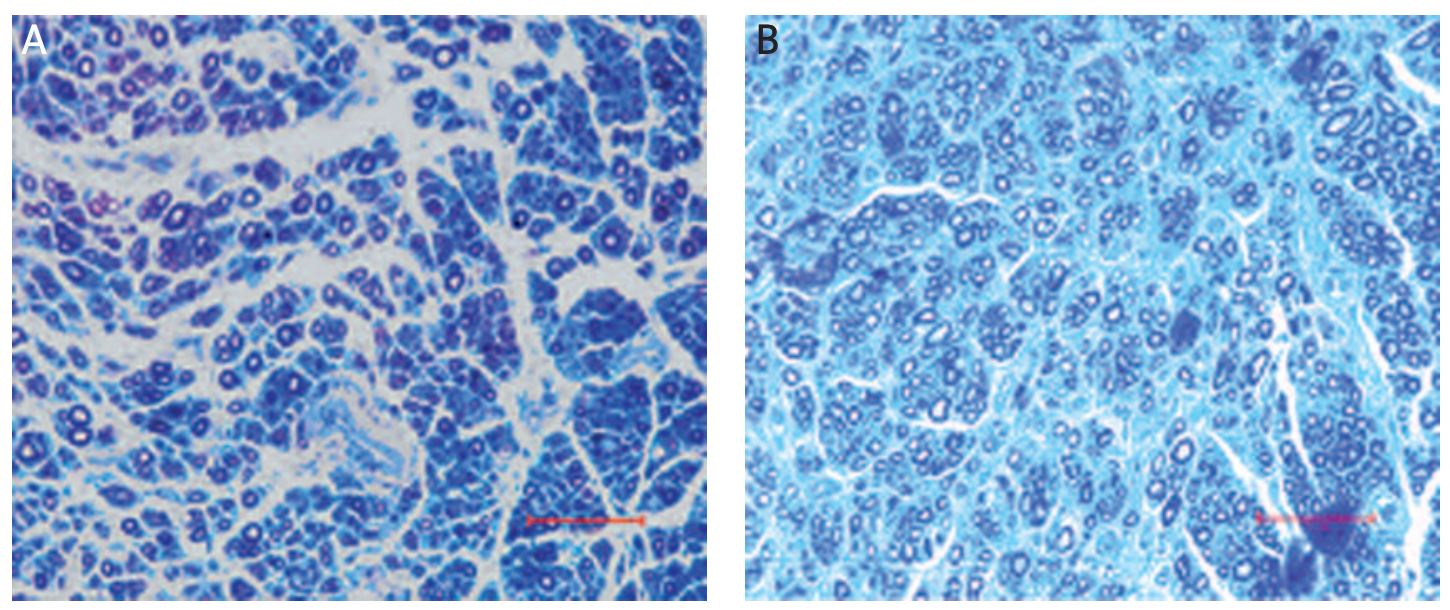

Figure 3. Improved nerve regeneration after ADSC graft. Semi-thin cross-sections of the distal portion of nerve graft were subjected to Toluidine blue stain 12 weeks post-surgery. A - the control, non-ADSC-laden graft group showed impaired regeneration with thin remyelinization. B - the ADSC-laden graft showed a higher density of well-myelinated nerve fibres. Scale bar $=50 \mu \mathrm{m}$

Table III. Regeneration of myelinated fibre $(n=6)$

\begin{tabular}{|lccc|}
\hline Group & $\begin{array}{c}\text { Myelinated fibre number } \\
{\left[\mathrm{root} / \mathrm{mm}^{2}\right]}\end{array}$ & $\begin{array}{c}\text { Myelin sheath thickness } \\
{[\mu \mathrm{m}]}\end{array}$ & $\begin{array}{c}\text { Myelinated fibres/total nerves } \\
{[\%]}\end{array}$ \\
\hline Control & $1378 \pm 91$ & $0.47 \pm 0.07$ & $39.63 \pm 3.50$ \\
\hline ADSC-treated & $1671 \pm 122^{*}$ & $0.92 \pm 0.09^{*}$ & $50.88 \pm 6.08^{*}$ \\
\hline
\end{tabular}

Values were mean $\pm S D,{ }^{*} p<0.05$ compared to control group 
myelinated fibres (Figure $3 \mathrm{~A}$ ). The percentages of nerve fibre density and nerve fibre diameter were significantly higher in the experimental group compared to the control group (Table III). These data indicate greater axonal regeneration in ADSC-laden acellular nerve grafts than in non-ADSC-laden grafts.

\section{Discussion}

Cell transplantation has emerged as a novel therapeutic approach for peripheral nerve defects. The ideal transplantable cells should be easily accessible, proliferate in culture and successfully integrate into host tissue with immunological tolerance [20]. Adipose-derived stem cells can be isolated simply by conventional liposuction procedures from abundant subcutaneous fat deposits. Furthermore, these cells can be expanded in culture for extended periods and proliferate rapidly $[13,21]$.

In the present study, we provided several lines of evidence that ADSC implantation could promote the repair of 10-mm nerve defects in acellular nerve: (i) improved walking behaviour as measured by footprint analysis, (ii) increased conservation of muscle-mass ratio of gastrocnemius and soleus muscles, (iii) increased nerve conduction velocity, and (iv) increased the number of myelinated fibres within the graft. These data indicate that ADSCs have great potential to promote the regeneration of peripheral nerve.

However, it is important to note that we only examined the effects of ADSC implantation on the regeneration of peripheral nerve 12 weeks after the grafting, which is one limitation of the present study. Future multiple-time-point and long-term investigations are necessary to find out how long implanted ADSCs can promote the peripheral nerve regeneration and at what time point the ADSCs exhibit the best effects.

In conclusion, our study demonstrated that ADSCs promote peripheral nerve repair in a rat model. Although the detailed mechanism by which ADSCs promote peripheral nerve regeneration is being investigated in our lab, our results reported here suggest that ADSC transplantation represents a powerful therapeutic approach for peripheral nerve injury.

\section{Acknowledgments}

This study was supported by grants from Shenyang Science and Technology Development Fund (No. F10-205-1-69) and Liaoning Science and Technology Development Fund (No. 2010225029), and Heilongjiang Youth Science Fund (No. QC2010040).

\section{References}

1. Pittenger MF, Mackay AM, Beck SC, et al. Multilineage potential of adult human mesenchymal stem cells. Science 1999; 284: 143-7.
2. Cuevas P, Carceller F, Dujovny $M$. Peripheral nerve regeneration by bone marrow stromal cells. Neurol Res 2002; 24: 634-8.

3. Cuevas P, Carceller F, Garcia-Gomez I. Bone marrow stromal cell implantation for peripheral nerve repair. Neurol Res 2004; 26: 230-2.

4. Chen CJ, Ou YC, Liao SL. Transplantation of bone marrow stromal cells for peripheral nerve repair. Exp Neurol 2007; 204: 443-53.

5. Dong Wang, Xiao-Lin Liu, Jia-Kai Zhu. Bridging small-gap peripheral nerve defects using acellular nerve allograft implanted with autologous bone marrow stromal cells in primates. Brain Res 2008; 1188: 44-53.

6. Zuk PA, Zhu M, Mizuno H. Multilineage cells from human adiposetissue: implications for cell-based therapies. Tissue Eng 2001; 7: 211-28.

7. Lee TH, Yoon JG. Intracerebral transplantation of human adipose tissue stromal cells after middle cerebral artery occlusion in rats. J Clin Neurosci 2008; 15: 907-12.

8. Li X, Gong P, Liao D. In vitro neural/glial differentiation potential of periodontal ligament stem cells. Arch Med Sci 2010; 6: 678-85.

9. De Ugarte DA, Morizono K, Elbarbary, A. Comparison of multi-lineage cells from human adipose tissue and bone marrow. Cells Tissues Organs 2003; 174: 101-9.

10. Strem BM, Hicok KC, Zhu M. Multipotential differentiation of adipose tissue-derived stem cells. Keio J Med 2005; 54: 132-41.

11. Gimble JM, Katz AJ, Bunnell BA. Adipose-derived stem cells for regenerative medicine. Circ Res 2007; 100: 1249-60.

12. Yoshimura H, Muneta T, Nimura A. Comparison of rat mesenchymal stem cells derived from bone marrow, synovium, periosteum, adipose tissue, and muscle. Cell Tissue Res 2007; 327: 449-62.

13. Liao D, Gong P, Li X, Tan Z, Yuan Q. Co-culture with Schwann cells is an effective way for adipose-derived stem cells neural transdifferentiation. Arch Med Sci 2010; 6: 145-51.

14. Xu YF, Liu L, Li Y. Myelin-forming ability of Schwann celllike cells induced from rat adipose derived stem cells in vitro. Brain Res 2008; 1239: 49-55.

15. Bain JR, MacKinnon SE, Hunter DA. Functional evalution of complete sciatic, peroneal, and posterior tibial nerve lesions in the rat. Plast Reconstr Surg 1989; 83: 129-36.

16. de Medinaceli L, Freed WJ, Wyatt RJ. An index of the functional condition of rat sciatic nerve based on measurements made from walking tracks. Exp Neurol 1982; 77: 634-43.

17. Carlton JM, Goldberg NH. Quantitating intergrated muscle function following reinnervation. Surg Forum 1986; 37 : 611-2.

18. Newman JP, Verity AN, Hawatmeh S. Ciliary neurotrophic factor enhances peripheral nerve regeneration. Arch Otolaryngol Head Neck Surg 1996; 122: 399-403.

19. Zhi Li. Effects of local release of hepatocyte growth factor on peripheral nerve regeneration in acellular nerve grafts. Exp Neurol 2008; 214: 47-54.

20. Tohill M, Terenghi G. Stem-cell plasticity and therapy for injuries of the peripheral nervous system. Biotechnol Appl Biochem 2004; 40: 17-24.

21. Zuk PA, Zhu M, Ashjian P. Human adipose tissue is a source of multipotent stem cells. Mol Biol Cell 2002; 13: 4279-95. 